\title{
Comparative Summary of the Fish Renal Structure, Using the Brown Trout (Salmo trutta) as the Reference Model
}

\author{
A.D. Resende****, A. Lobo-da-Cunha***** and E. Rocha**,*** \\ * North Polytechnic Health Institute (IPSN), Gandra, Portugal \\ ** Institute of Biomedical Sciences Abel Salazar (ICBAS), Porto University, Porto \\ *** Interdisciplinary Centre for Marine and Environmental Research (CIIMAR), Porto
}

Fish renal morphology has been studied since the 1960's, but is still incomplete for most species, even for some of the most studied. The functional and morphological diversity and specialization of the fish kidney, due to environmental adaptations, makes this a large subject that remains understudied. References to studies on fish renal structure are given in Table 1. Although authors as Hentschel and Elger contributed to the knowledge of fish renal morphology in a comparative perspective, the knowledge concerning this issue is still reduced. Here we give a short comparative summary of fish renal morphology, using as baseline model the brown trout.

As is usual in fish, trout kidney is a dorsal retroperitoneal organ located along the body cavity. Two differentiated parts of fish kidney are clearly identified: the head and the trunk kidney. The head kidney is composed essentially by hematopoietic tissue, in which it can be found undifferentiated stem cells, blast cells, immature and mature stages of red and white blood cells, as well as a great amount of pigment granules (melanin) essentially in association with macrophages - the melanomacrophages. In some teleosts, the latter cells are organized in melanomacrophage centers, whereas in salmonids those cells appeared widespread. Renal tubules are very scarce in this portion but become more frequent towards the caudal part. The trunk kidney possesses numerous nephrons and ducts that are nevertheless surrounded with hematopoietic tissue. Actually, this organ appears as a fusion of two kidneys in salmonids, whereas in other fish species, such as carp Cyprinus carpio and goldfish Carassius auratus, the two portions are macroscopically distinct. The characterization of nephron segments varies among fishes, because some species lack some segments, and also the cellular structure can be different within the same portion for different species, especially because the major function of this organ is directly correlated with fish habitat under adaptation to water of different salinities. Some fish lack renal corpuscules altogether.

In salmonids, nephron segmentation has been studied for more than 40 years at light and electron microscopy levels. The "proximal nephron" is composed of the glomerular epithelium, the epithelium of Bowman's capsule, a short neck segment, the proximal tubule (with a first and a second portion) and the intermediate segment. The existence of a distinct neck segment as well as an intermediate segment is not very clear and still produces some controversy. The "distal nephron" is constituted by the distal tubule, the collecting tubule and the collecting duct. The latter established the link between the nephron and the collecting ducts that in turn coalesce forming the mesonephric duct or ureter. In some fish species, the posterior part of the ureter can possess an enlarged region, which corresponds to the urinary bladder.

The mentioned glomerular and multisegmental nephron is considered the central nephron type, which can be subdivided in other types. As above stated, some fishes do not possess glomeruli, and their kidneys are termed aglomerular. This type is predominantly found in marine species and euryhaline fishes in sea water, such as toadfish (family Batracoididae), anglerfish (order Lophiiformes), sea horses (genus Hippocampus) and needlefish (family Belonidae). Contrary to the multisegmental nephron, other type denominated as "atubular" nephron may be found in Myxinoidea species, though it is not present in other agnathan subgroups such as Petromyzontia (lampreys). Chondrostei, Holostei and Teleosts, such as eels, salmonids and ostariophysids (e.g. carps and catfishes) possess a long multisegmental nephron, whereas in marine teleosts of different orders, such as percids (family Percidae), killifish (order Cyprinodontiformes), flounder (order Pleuronectiformes) and sticklebacks (family Gasterosteidae) the nephron is shorter because the distal segment is absent. In general, and 
when comparing with freshwater species, marine fishes exhibit smaller glomeruli and a shorter segment I of proximal tubule. These features are in accordance to their different physiology, as marine species have to accomplish low filtration and low reabsorption rates in order to excrete more concentrated urine, contrary to the highly diluted urine produced from freshwater species.

This summary highlights the diversity of fish kidney morphology and the lack systematic data on a reasonable fraction of the huge diversity of fish species. This work aims to be a good baseline for launching studies to know which factors may govern the morphological variations and their functional consequences, and is also relevant for interpreting changes in toxicological contexts.

Table 1. Summary of published studies about fish kidney.

\begin{tabular}{lll}
\hline Species & Habitat & References \\
\hline English sole (Parophrys vetulus) & Marine & {$[1]$} \\
Bluegill (Lepomis macrochirus) & Freshwater & {$[2]$} \\
Southern flounder (Paralichthys lethostigma) & Marine & {$[2]$} \\
Pink salmon (Oncorhynchus gorbuscha) & Marine & {$[3]$} \\
Sea lamprey (Petromyzon marinus) & Marine & {$[4,5,6,7,8]$} \\
Atlantic hagfish (Myxine glutinosa) & Marine & {$[9]$} \\
Trouts (Salmo aguabonita, S. gairdneri, S. trutta, Salvelinus & Freshwater & {$[10]$} \\
fontinalis) & & \\
Elasmobranch dogfish (Scyliorhinus canaliculus) & Marine & {$[11]$} \\
Rainbow trout (Oncorhynchus mykiss) & Freshwater & {$[12,13,14]$} \\
Pacific salmons (Oncorhynchus spp) & Marine & {$[15]$} \\
Sturgeon (Acipenser nacarii) & Freshwater & {$[16]$} \\
Coelachant (Latimeria chalumnae) & Marine & {$[17]$} \\
\hline
\end{tabular}

References

1. Bulger, R. E. and Trump, B. F., American Journal of Anatomy 123: 195-225, 1968

2. Hickman, C. P. and Trump, B. F., The Kidney. Academic Press Inc., New York, 1969

3. Newstead, J. D. and Ford, P., Canadian Journal of Zoology 38: 1-7, 1960

4. Youson, J. H. and McMillan, D. B., American Journal of Anatomy 127: 207-231, 1970

5. Youson, J. H. and McMillan, D. B., American Journal of Anatomy 127: 233-257, 1970

6. Youson, J. H. and McMillan, D. B., American Journal of Anatomy 130: 55-71, 1971

7. Youson, J. H. and McMillan, D. B., American Journal of Anatomy 130: 281-303, 1971

8. Youson, J. H. and McMillan, D. B., American Journal of Anatomy 131: 289-313, 1971

9. Heath-Eves, M. J. and McMillan, D. B., American Journal of Anatomy 139: 309-333, 1974

10. Anderson, B. G. and Loewen, R. D., American Journal of Anatomy 143: 93-113, 1975

11. Hentschel, H., American Journal of Anatomy 190: 309-333, 1991

12. Kendall, M. W., Anatomical Record 190: 441, 1978

13. Oulmi, Y. et al., Diseases of Aquatic Organisms 21: 35-52, 1995

14. Oulmi, Y. et al., Ecotoxicology and Environmental Safety 32: 39-50, 1995

15. Maksimovich, A. A. et al., Journal of Evolutionary Biochemistry and Physiology 36: 334-345, 2000

16. Ojeda, J. L. et al., Anatomical Record Part A-Discoveries in Molecular Cellular and Evolutionary Biology 272A, 563-573, 2003

17. Jarial, M. S. and Wilkins, J. H., Journal of Fish Biology 76: 655-668, 2010 